\title{
Geomagnetic Survey to Explore High-Temperature Geothermal System in Blawan-ljen, East Java, Indonesia
}

\author{
Yunus Daud ${ }^{1,2^{*}}$, Syamsu Rosid ${ }^{1,2}$, Fikri Fahmi $^{1}$, Faris Maulana Yunus ${ }^{2}$ and Reza Muflihendri ${ }^{2}$ \\ ${ }^{1}$ Master Program in Geothermal Exploration, Graduate Program of Physical Science, Universitas Indonesia, Jakarta, Indonesia \\ ${ }^{2}$ Study Program of Geophysics Faculty of Mathematics and Natural Science, Universitas Indonesia, Depok, Indonesia
}

\begin{abstract}
Ijen geothermal area is high-temperature geothermal system located in Bondowoso regency, East Java. It is categorized as caldera-hosted geothermal system which is covered by quaternary andesitic volcanic rocks with steep topography at the surrounding. Several surface thermal manifestations are found, such as altered rocks near Mt. Kukusan and a group of Blawan hotsprings in the northern part of the caldera. Geomagnetic survey was conducted at 72 stations which is distributed inside the caldera to delineate the existence of hydrothermal activity. Magnetic anomaly was obtained by reducing total magnetic measured on the field by IGRF and diurnal variation. Reduction to pole (RTP) method was applied with geomagnetic inclination of about $-32^{0}$. In general, the result shows that high magnetic anomaly is distributed at the boundary of study area, while low magnetic anomaly is observed in the centre. The low anomaly indicates demagnetized rock that probably caused by hydrothermal activity. It has a good correlation with surface alteration observed close to Mt. Kukusan as well as high temperature reservoir drilled in the centre of caldera. Accordingly, the low magnetic anomaly also presents the possibility of geothermal reservo ir in Ijen geothermal area.
\end{abstract}

\section{Introduction}

Ijen Volcanic Complex is located in the Bondowoso, West Java, Indonesia. Expectation of geothermal system appearance in the volcanic complex is indicated by the occurrence of Blawan hotspring in the northern part of caldera rim and steam heated extremely acid sulphate water on Ijen crater as the only surface manifestation in this area. The hot spring express an outflow of the system, while the Ijen crater indicates a young volcano which is uneconomical to be developed. Therefore, it is necessary to do further research to find an appropriate location to be targeted in such challenging hidden geothermal system.

In 2017, magnetic survey had been conducted over Ijen geothermal prospect area at 72 stations. Magnetic method is carried out to measure magnetic field variations in the earth's surface. The studies of magnetic anomalies are often useful for investigating high temperature geothermal systems hosted by Quaternary volcanic rocks [1]. These anomalies represent the demagnetization of reservoir rocks caused by hydrothermal processes due to thermal fluid and rock interactions. In this study, we used a reduce to pole (RTP) technique for imaging total force of magnetic anomalies. RTP transformation delineates the hydrothermally demagnetised rock which is shown as negative anomalies [2]. This paper presents the results of magnetic anomaly, RTP anomaly and the upwardcontinuation anomaly which were then interpreted to get a conclusion of the geothermal prospect zone in the Ijen Volcanic Complex.

\section{Regional Geology}

The Ijen Volcanic Complex (IVC) is located in East Java. The Old Ijen volcano is thought to form around the Pleistocene [3]. The caldera itself is formed by Plinian eruption, ejecting $80 \mathrm{~km} 3$ of volcanic material, back to the 0,2-0,05 Ma [4]. Currently, the product is revealed partly at the northern part. Meanwhile, in the southern part, it has been covered by younger volcanoes.

The post-caldera volcanoes are classified into two groups: Caldera Rim Volcanoes and Intra Caldera Volcanoes [5]. Some fault are found in the caldera and extents right in the centre of the caldera, strikes the remains caldera rim in the north and tear down the wall into a steep creek. Here in IVC, several structures that occurred are Blawan fault, Kawahwurung fault, Krepekan fault, Cemara-Kukusan fault, KalipahitBanyulinu fault, Djampit fault, Rante fault, PawenanBlau fault and Kendeng-Merapi fault (Fig.1).

The deformation may caused by tectonic activity, magma refilling in the chamber, or collaboration of those two that reactivate the caldera floor structures. Hot springs in Blawan area indicating that secondary permeability will affect the geothermal manifestation occurrences.

* Corresponding author: ydaud@sci.ui.ac.id 


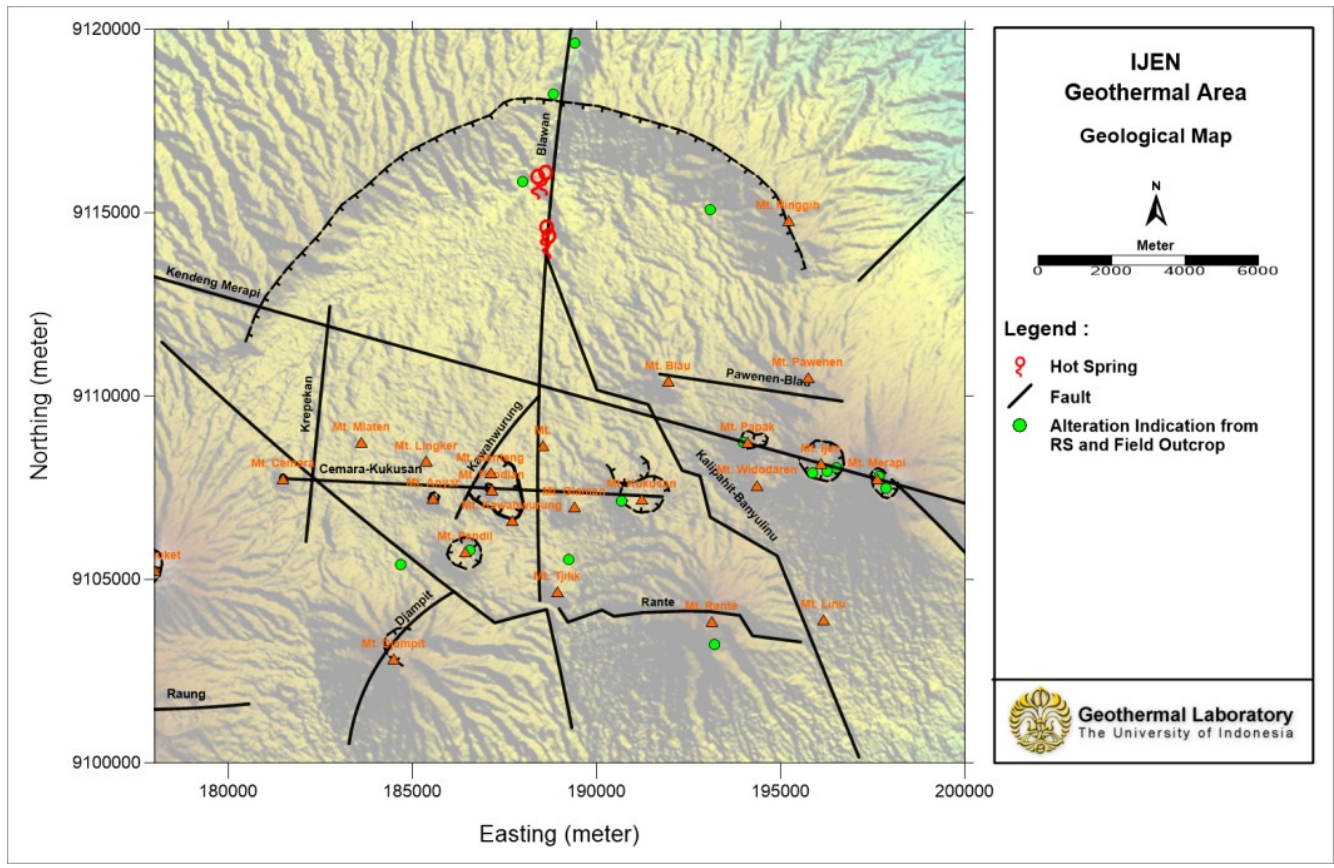

Fig. 1. Geological Map of Ijen Geothermal Area

\section{Method}

\subsection{Acquisition and Data Processing}

The acquisition of magnetic data had been carried out in the Ijen geothermal prospect area in 2017. The magnetic measurements were conducted using a Proton Precision Magnetometer (PPM). A total of 72 magnetic stations were measured with 1 to $1.5 \mathrm{~km}$ grid spacing and distributed inside the caldera rim.

Furthermore, several corrections had been applied to the measured magnetic field data set in order to get the anomaly reflected from the geological target. At the first step, the contour map of the observed magnetic field was reduced for diurnal variation. Then the magnetic data was corrected for IGRF to remove the normal geomagnetic field. By reducing the total magnetic field with diurnal variation and IGRF correction then the magnetic anomalies associated with local magnetic variations of rocks can be obtained.

Moreover, the reduction to the pole (RTP) technique was carried out by reducing the magnetic data to the pole with the angle of inclination $-32^{\circ}$. It is used to get the response of geothermal reservoir located just below the low magnetic anomaly. The upward continuation was also conducted to reduce the effects of shallow/local anomaly. In this case, we performed the continuation to a height of 250 meters.

\section{Magnetic Signature of Blawan-ljen Geothermal System}

\subsection{Magnetic Anomaly}

The magnetic anomaly map of Ijen geothermal prospect area is shown in the Fig. 2 with the highest value of about $1984 \mathrm{nT}$, while the lowest magnetic anomaly value of about $-1206 \mathrm{nT}$.

The low magnetic anomalies were found covering almost the entire study area and they were surrounded by high magnetic anomalies. Several bipolar anomalies were identified in the three locations. In the southeast area, it is probably associated with the existence of Mt Kukusan while anomaly in the southwest area could be correlated with Mt Pendil. The other anomaly in the northern part of the study area has not been clearly determined regarding possible correlation with the geological condition in this area.

\subsection{Reduce to Pole (RTP)}

The result of reduction to the pole (RTP) can be seen in Fig. 3. The focus in the investigation for the location of the geothermal reservoir is low (negative) anomaly area due to the hydrothermal demagnetization. The negative magnetic anomalies occur over the northern part of the study area and extend to the southeast area. 


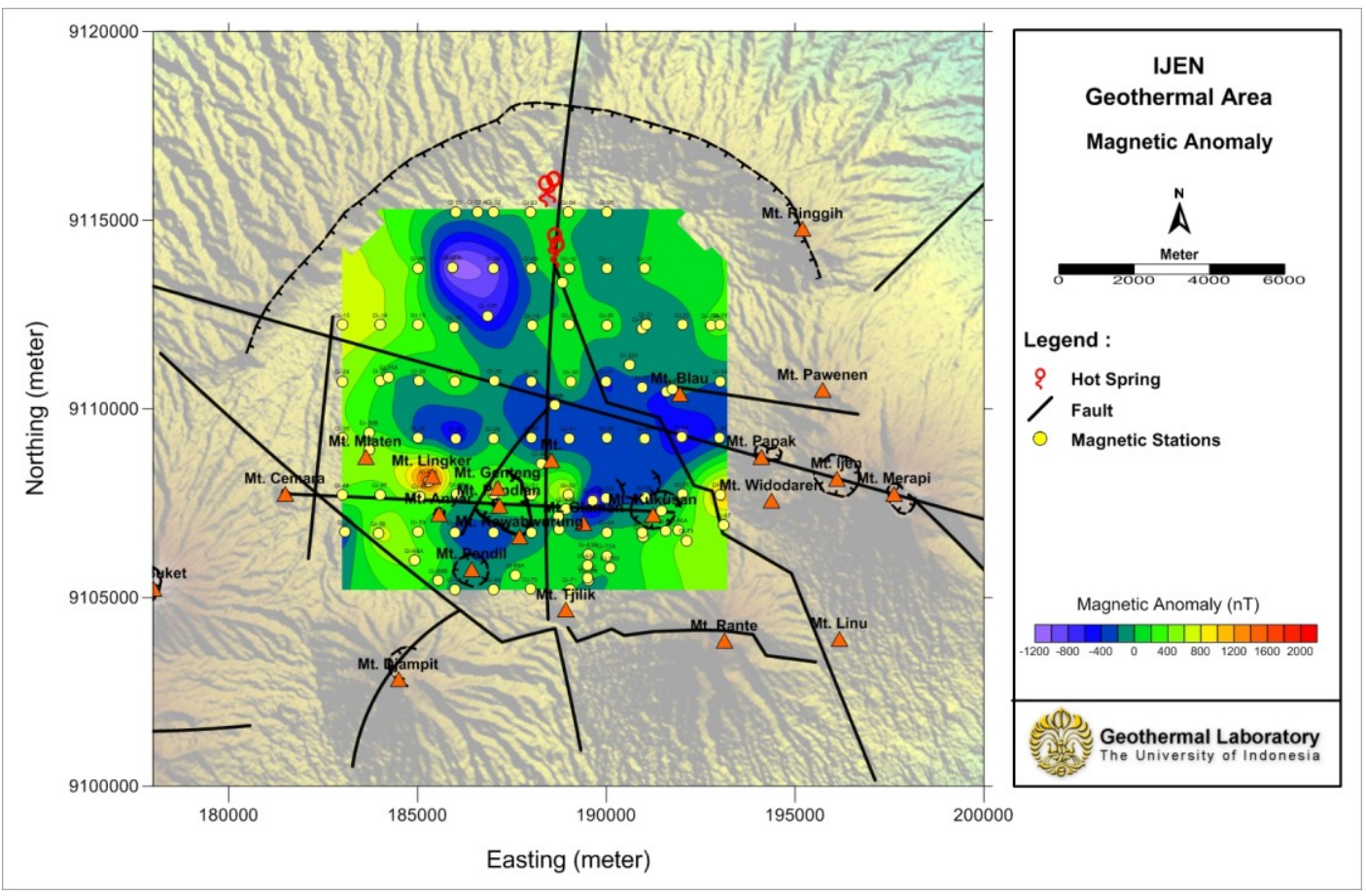

Fig. 2. Magnetic Anomalies over Ijen Geothermal Area

The pattern of negative anomaly found in the centre of the study area is probably associated with the presence of hydrothermal demagnetised rocks of Mt Kukusan. It is supported by the presence of surface alteration observed close to Mt. Kukusan.

The location of the prospect zone is also strengthened by the intersection of several faults; Blawan fault, Cemara-Kukusan fault, and Kawahwurung Fault which could form a high permeable zone.

\subsection{Upward Continuation}

Fig. 4 shows the upward continuation anomaly map. Generally, the pattern of the high and low magnetic anomaly in the upward continuation map yields the same pattern with the RTP anomaly.

The upward continuation anomaly represents a regional anomaly. As shown in the result, it further strengthens that the negative magnetic anomalies area occured in the northern part of the study area and extended to the southeast which could become the prospect zone in Blawan Ijen geothermal area.

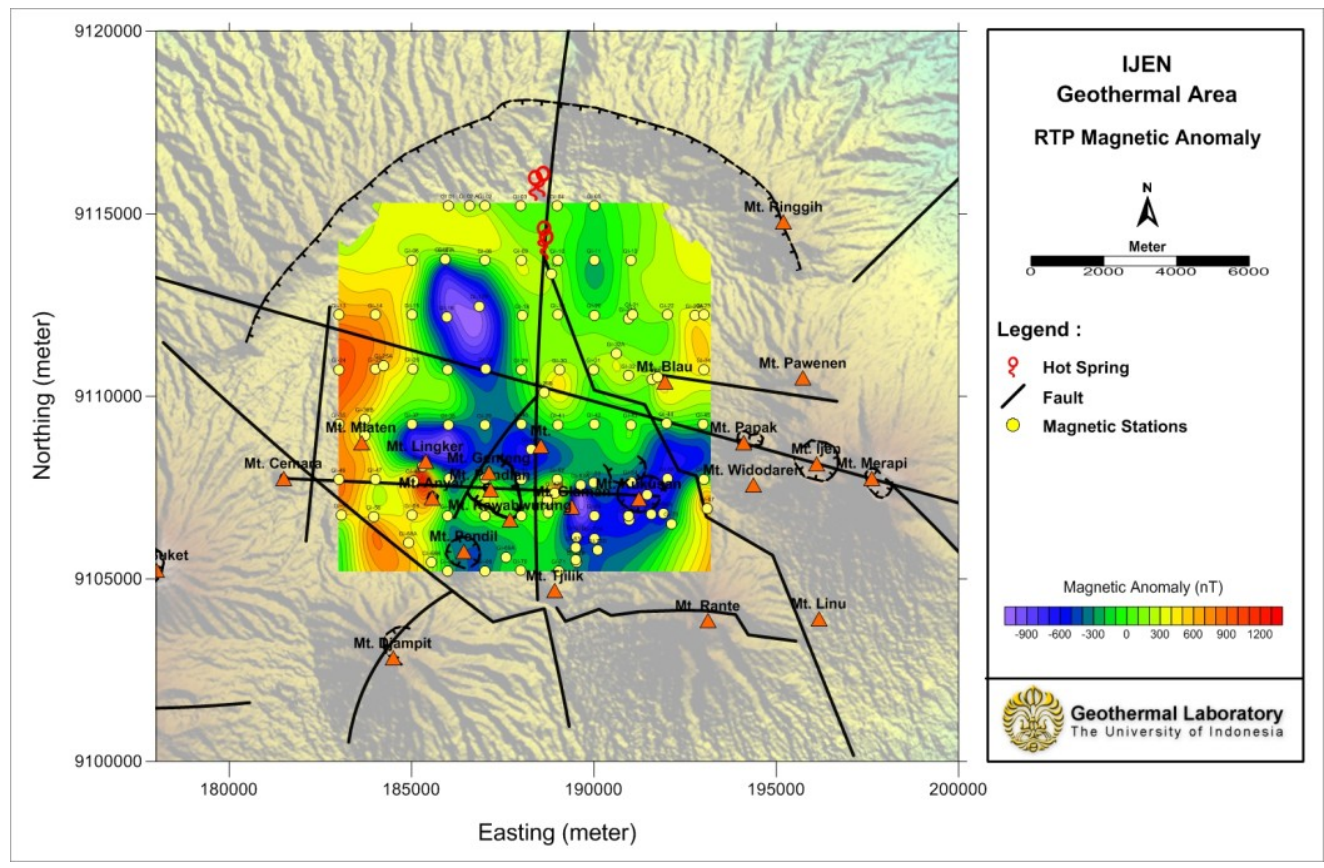

Fig. 3. The result of Reduce to Pole (RTP) of Magnetic Anomalies of Ijen Geothermal Area 


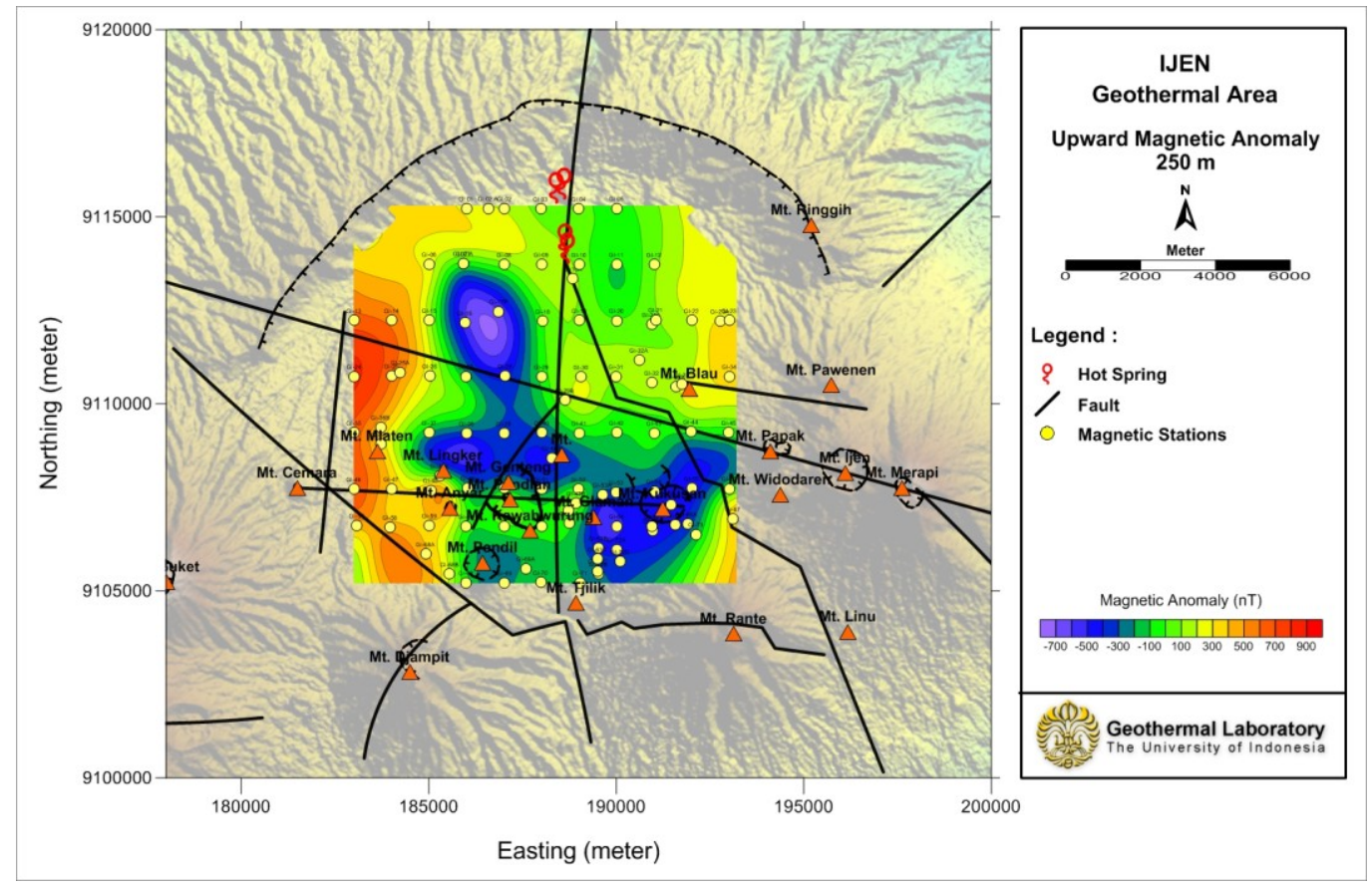

Fig. 4. The Map of Upward Continuation Anomalies of Ijen Geothermal Area

\section{Conclusion}

This study was carried out in the Ijen geothermal prospect area. The presence of surface manifestation is very rarely, only Blawan hotspring found in the northern part of study area and extremely acid fluid on the top of Mt. Ijen. Therefore, the magnetic method was conducted to determine the location of geothermal prospect zone between Blawan area and Mt. Ijen. A negative anomaly is identified in the center (North to southeast) of the study area and it was interpreted as the hydrothermal demagnetised rocks of Mt Kukusan. This negative anomaly has good correlation with the presence of altered rock found near Mt Kukusan. The intersection of several faults; Blawan fault, Cemara-Kukusan fault and Kawahwurung Fault in the center of study area supports the possibility of geothermal prospect zone location.

\section{Acknowledgement}

We greatly appreciate Directorate of Research and Community Engagement of Universitas Indonesia (DRPM UI) for funding this project through PITTA program.

\section{References}

1. S. Soengkono New Zealand: Geothermics 30, 443459 (2001)

2. S. Soengkono, Proceeding 36th New Zealand Geothermal Workshop 24-26 November 2014

3. M. Ben Rabha, M.F. Boujmil, M. Saadoun, B. Bessaïs, Eur. Phys. J. Appl. Phys. (to be published)

4. R.W. Van Bemmelen, The Geology of Indonesia Vol. IA: General Geology of Indonesia and Adjacent Achipelagoes (Government Printing Office, The Hague, 1949)

5. K. Sitorus, Stratigrafi dan Geokimia Kaldera Idjen,

6. Jawa Timur, Indonesia. Proceedings PIT XIX Ikatan Ahli Geologi Indonesia, Bandung (1997)

7. H.K. Handley, C.G. Macpherson, J.P. Davidson, K. Berlo, Journal of Petrology 48, 1155-1183. Oxford University, (2007) 